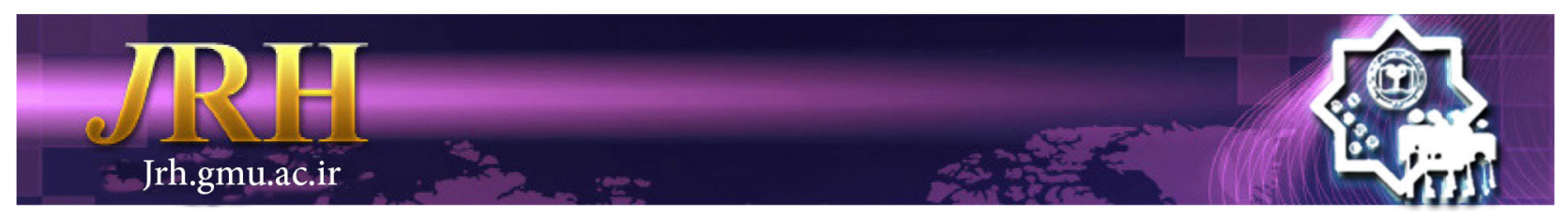

\title{
Sociological analysis of social harms and their influence on health
}

Sedighe Arabi ${ }^{1}$

\author{
Journal of Research \& Health \\ Social Development \& Health Promotion \\ Research Center \\ Vol. 9, No.1, Jan \& Feb 2019 \\ Pages: 1 - 2 \\ DOI: $10.29252 / j r h .9 .1 .1$ \\ Letter to Editor
}

1. Correspondence to: Social Development \& Health Promotion Research Center, Gonabad University of Medical Sciences, Gonabad, Iran Email: sedighe.arabi@yahoo.com

Received: 24 Jul 2018

Accepted: 18 Oct 2018

How to cite this article: Arabi A. Sociological analysis of social harms and their influence on health. J Research \& Health2019; 9(1): 1- 2.

\section{Dear Chief in Editor}

Social health, along with physical and mental health, constitute the main pillars of health. The simultaneous dependence of social health on the characteristics of society and the individual makes a society to be healthy in which there is equal access for everyone to necessary goods and services for full functioning as a citizen. National security takes place when not only people have no harm but also there is a public effort to run a healthy society. The sense of security comes from itself or from the society in which one lives. Social harm is increasingly on the rise, and it is essential to take necessary measures for containing these threats. Social harm, as a serious threat to the individuals' health, faces them with danger. It is caused by several factors such as population uncontrolled growth, urbanization, mechanization of life, the breakup of interpersonal relationships, and the influence of the peer group which can affect the quality of life. Social harms can cause a lot of problems for individuals in society, have a negative effect on their physical and mental health, reduce their life quality and have destructive effects on the community development process [1]. Social harm has been considered by scholars in human society since a long time ago. At the same time as the expansion of the industrial revolution and the scope of needs, the deprivations from the impossibility of meeting demands and the needs of life have led to a widespread expansion of corruption, revenge, crime, wandering, theft, sexual deviations and other harms. Social harm or deviation refers to any type of individual or collective moral action which is not organized in the framework of principles and the collective action rules of the community in where the activity is carried on. Thus they are faced with legal prohibition and moral-social constraints. Due to this, deviants try to hide their deviations from the law enforcements, public morals and social order. In other words, social pathology can be considered as the study of unorganized functions basics. In fact, social pathology studies the causes and methods of preventing and treating anomalies and social harms such as addiction, poverty, suicide, prostitution, divorce, unemployment, spree and street children.[2].

Various social factors affect social harms, including the economic status of the family (excessive poverty or well-being), broken families with intellectual and emotional gap, morally weak and unrestricted families, socializing with unsuitable friends and the pressure of peer group, the lack of parents' and children awareness about the principles of education and training as well as life skills, unemployment, job satisfaction/ 
dissatisfaction, marital status, population density, migration, injustice, drugs, age characteristics and ages of puberty (Such as selforientation, seeking autonomy, disobedience of elders and individual identity disorder), pseudo incomes and economic imbalance or high class distance in the community, the lack of appropriate culture for using today technologies such as Internet and unauthorized satellites, and the negative impact of inappropriate content in the mass media which lead people to show high-risk behaviors and social harms and commit a crime[3].

If social harms, including material and economic damages, is likely to decline in a society, and the family does not adapt itself to this conditions, it will necessarily move towards collapse. During last decade, these severe changes were a reason of solidarity reduction as well as family communication weakness which have no effect on life [4].

In some studies, social class, family support, adherence to ethnic customs, age, and trust in law enforcement were the main variables affecting the sense of peace and social security among female students. These five variables, totally predicted $89.5 \%$, of sense of peace, social security and health. Besides, the mean of social harm and life quality was 29/84 and 64/8, respectively. $[2,5]$ It can be said that social harms threaten the mental and physical health of community members. Therefore, planning for the promotion of psychosocial health strategies within society seems necessary. The social harms in a community prevents people from learning, attending educational sessions, accessing services and citizenship activities which is psychosocially harmful. Policy makers, planners, and community decisionmakers can reduce the harms and assure the health of community by the scientific review of community policies and economical programs. Besides, the community members should also be empowered by education to increase their sense of belonging and social responsibility. Furthermore, appropriate actions can be taken by adjusting suitable programs for each region and identifying the community risk factors. The goal of psychosocial health promotion, is providing the sense of happiness, security, hope, life satisfaction for public, increasing the community skills to deal with stress, promoting social communication and life skills as well as parenting practices [3].

\section{References}

1- Koohi K. Youth and Social harm. Quarterly Guardz Danesh Eastern Azerbaijan2013; 3(10): 27-47.

2- Afkhami Aghda M, Naeem Yavari M, Maleksabet

H, Mehrparvar Ah, Falahati M, Laeh M. Investigating the relationship between social damages and the quality of life in Yazd city. Journal of Shahid Sadoughi University of Medical Sciences2016; 3(24): 241-50.

3- Tabatabaei SM, Atashnafas E. Half of the damage to the predisposing and preventing factors of social harm in students. Journal of Roshd2011; 4(6): 8-16.

4- Fathi S, Fadavi J. An analysis of social problems and its effective factors in 1999-2008 among the youth. Sociological Studies of Youth Journal2013; 8(3): 121-44. 5- Abdoli A, Mohammadi J, Ebrahimi R. The analysis of felling security social in urba tourists (case study: The domestic tourist of Esfahan city). Journal of Geography and Planning2015; 50(18): 235-57.

Copyright(C) 2016 ASP Ins. This open-access article is published under the terms of the Creative Commons Attribution-NonCommercial 4.0 International License which permits Share (copy and redistribute the material in any medium or format) and Adapt (remix, transform, and build upon the material) under the Attribution-NonCommercial terms. 